\title{
Dampak Elemen Customer Relationship Marketing Terhadap Loyalitas Pelanggan Rumah Makan Bebek 88
}

The Effect of Customer Relationship Marketing Towards Customer Loyalty at Bebek 88 Restaurant

perusahaan dalam mengambil langkah-langkah atau

\author{
Akhmad Fahrur Rozi, R.Andi Sularso, M. Dimyati \\ Magister Manajemen, Fakultas Ekonomi, Universitas Jember (UNEJ) \\ Jln. Kalimantan 37, Jember 68121 \\ E-mail: akhmadfahrur@yahoo.co.id
}

\begin{abstract}
Abstrak
Tujuan penelitian ini adalah Menyadari akan pentingnya customer intimasi, kepercayaan pelanggan, komitmen pelanggan dan kepuasan pelanggan, serta mengetahui kesuksesan dari Rumah Makan Bebek 88, maka peneliti tertarik untuk meneliti dan menguji "Dampak Elemen Costumer Reletionship Marketing Terhadap Loyalitas Pelanggan RM Bebek 88".. Objek yang diteliti adalah pelanggan Rumah Makan Bebek 88. Pada penelitian ini menggunakan metode purposive sampling dengan jumlah responden sebanyak 150 orang. Alat analisis yang digunakan dalam penelitian ini adalah Structural Equation Model (SEM) dengan pendekatan confirmatory. Hasil analisis data menunjukkan bahwa tidak ada pengaruh variabel customer intimacy terhadap loyalitas sedangkan valiabel kepercayaan, komitmen dan kepuasaan berpengaruh signifikan terhadap loyalitas Bebek 88 .
\end{abstract}

Kata Kunci: Costumer Reletionship Marketing, customer intimacy, kepercayaan, komitmen, kepuasaan dan loyalitas.

\begin{abstract}
The purpose of this study is to analyze the importance of customer intimacy, customer trust, customer commitment and customer satisfaction, and to know the success of Bebek 88 Restaurant, the researcher is interested to study and to test The Effect of Customer Relationship Marketing Towards Customer Loyalty at Bebek 88 Restaurant." The object of study is the customer of Bebek 88 Restaurant. In this study, the use of purposive sampling with 150 respondents is approached through Structural Equation Model confirmatory (SEM). The results shows that there is no relation in customer intimacy to the loyalty of the consumer, but commitment and satisfaction
\end{abstract}

Key Words: Customer reletionship Marketing, customer intimacy, trust, commitment, satisfaction and loyalty.

\section{Pendahuluan}

Persaingan dalam dunia usaha saat ini semakin ketat maka aspek pemasaran disini sangatlah penting, hal ini karena aspek pemasaran dipandang sebagai serangkaian prinsip untuk memilih pasar sasaran, mengevaluasi kebutuhan konsumen, dan laba bagi perusahaan (Sumarni, 2003:215). Salah satu manajemen yang harus dijalankan secara professional oleh perusahaan untuk menghadapi situasi dan kondisi persaingan yang semakin kompetitif ini adalah kemampuan manajemen pemasaran. Mempelajari dan memahami apa yang diinginkan oleh konsumen merupakan suatu hal yang sangat penting, karena hal ini dapat membantu pihak kebijakan-kebijakan tepat yang dapat membawa perusahaan kearah keberhasilan.

Menurut Webster (1994:65), selama ini pendekatan dalam pemasaran lebih menekankan pada konsep pemasaran transaksional (transactional marketing). Pemasaran transaksional merupakan konsep pemasaran yang bertujuan memperoleh pelanggan baru dan mengakhiri dengan penjualan. Pemasaran transaksional memandang proses pemasaran akan berakhir ketika transaksi jual beli telah terjadi, kemudian pemasar akan mengarahkan perhatian pelanggan untuk menciptakan transaksi berikutnya. 
Namun, penekanan yang diberikan di dalam aktifitas pemasaran sebaiknya tidak hanya pada proses dalam melakukan transaksi saja. Setelah adanya transaksi antara penjual dan pembeli, pihak pemasar (penjual) harus tetap memiliki suatu hubungan dengan pelanggannya. Para praktisi dan akademisi mulai menyadari pentingnya hubungan yang dilakukan antara pemasar dan pelanggan. Hal ini menjadikan dasar bagi konsep pemasaran relasional (relationship marketing) untuk berkembang (Gronroos, 1997:22).

Penelitian ini berfokus pada industri makanan yang memberikan tingkat customization tinggi pada saat penyedia produk pada pelanggan, menawarkan layanannya kepada pelanggannya secara individual untuk memenuhi kebutuhan dan preferensi pelanggannya. Hal ini sesuai dengan pendapat Sheth \& Parvatiyar (1995) yang mengatakan bahwa penerapan customer intimacy terdapat pada sebuah jasa atau layanan yang spesifik yang membangun hubungan secara individual (customized) antara pelanggan dengan pihak penyedia layanan. (Hoffman, 2002) menyatakan bahwa penerapan customer intimacy menjadi bermanfaat bagi pelanggan dan perusahaan tersebut jika perusahaan tersebut memiliki customized yang tinggi dengan melibatkan karyawan untuk menghantarkan layanan tersebut. Schnaars (dalam Tjiptono, 2002:24) bahwa pada dasarnya tujuan dari suatu bisnis adalah untuk menciptakan para konsumen atau pelanggan yang puas. Terciptanya kepuasan konsumen dapat memberikan sebuah manfaat, diantaranya hubungan antara perusahaan dan pelanggannya menjadi harmonis, memberikan dasar yang baik bagi pembelian ulang dan terciptanya loyalitas pelanggan dan untuk membentuk suatu rekomendasi dari mulut kemulut yang menguntungkan bagi produsen maupun konsumen.

Dengan adanya persaingan yang semakin ketat, dimana semakin banyak produsen yang terlibat dalam pemenuhan kebutuan dan keinginan konsumen, menyebabkan setiap perusahaan harus menempatkan fokus pada kepuasan pelanggan sebagai tujuan utama dari perusahaan. Selain itu juga produsen juga harus dapat menciptakan rasa loyalitas dari para pelanggannya. Menurut Griffin (2002:31) pelanggan yang loyal adalah mereka yang sangat puas dengan produk dan jasa tertentu sehingga mempunyai antusiasme untuk memperkenalkannya kepada siapapun yang mereka kenal.

Hal ini menjadi penting karena dengan mengelola customer intimasy, kepercayaan pelanggan, komitmen pelanggan dan kepuasan pelanggan yang merupakan faktor dasar yang mampu mendorong adanya rasa loyalitas pelanggan pada diri seorang pelanggan. Seperti halnya yang dilakukan oleh manajemen Rumah Makan Bebek 88. Menyadari akan pentingnya customer intimasy, kepercayaan pelanggan, komitmen pelanggan dan kepuasan pelanggan, serta mengetahui kesuksesan dari Rumah Makan Bebek 88, maka peneliti tertarik untuk meneliti dan menguji "Dampak Elemen Costumer Reletionship Marketing Terhadap Loyalitas Pelanggan RM Bebek 88".

\section{Metode Penelitian}

Jenis penelitian yang digunakan adalah penelitian penjelasan (explanatory research), dimana bertujuan untuk menjelaskan hubungan-hubungan antara satu variabel dengan variabel lainnya atau bagaimana suatu variabel mempengaruhi variabel lainnya dan juga termasuk dalam penelitian konfirmatori (confirmatory research), confirmatory research adalah peneletian yang bertujuan menguji hubungan teoritis antara variabel berdasarkan data empiris melalui pengujian hipotesis. Untuk melaksanakan penelitian tersebut, pengambilan data dilakukan dengan cara penyebaran kuisioner yang datanya dikumpulkan dari sampel atas populasi untuk mewakili seluruh populasi. Metode analisis data menggunakan SEM dengan menggunakan program software Amos (Analysis Of Moment Structure) versi 5.0.

\section{Jenis dan Sumber Data}

Jenis data yang dianalisis dalam penelitian ini adalah data primer. Data primer adalah data yang diperoleh langsung dari sumber data yang dikumpulkan secara khusus dan berhubungan langsung dari permasalahan yang diteliti. Data primer dalam penelitian ini adalah berupa jawaban dari pertanyaan kuisioner dan wawancara terhadap pemilik rumah makan bebek 88 .

Metode pengumpulan data dalam studi ini dilakukan dengan menggunakan metode surve, yakni menggunakan kuisoner yang berisi butir-butir pengukuran konstruk atau variable yang digunakan dalam metode penelitian ini. Pengumpulan data dilakukan secara langsung dengan meminta kesediaan responden untuk mengisi kuisoner yang dilakukan dengan mendatangani pelanggan yang sedang melakukan transaksi di RM bebek 88

\section{Populasi dan Sampel}

Populasi penelitian ini adalah pelanggan RM bebek 88, Sampel adalah 150 responden Teknik sampling yang digunakan adalah purposive sampling, dimana metode ini digunakan dengan cara memilih responden yang benarbenar pelanggan Bebek 88, dengan syarat atau kriteria sebagai responden adalah sebagai berikut :1. Responden merupakan pelanggan bebek 88 yang melakukan transaksi lebih dari 3 kali.2. Konsumen yang dijadikan responden minimal bisa memutuskan apa yang harus dipesan.

\section{Metode Analisis Data}

penelitian ini menggunakan metode analasis data Structural Equation Model (SEM).

\section{Hasil Penelitian}

Konstruk pada teknik confirmatory factor analysis disebut dengan laten variabel (variabel yang tidak dapat diukur secara langsung) dan indikator adalah observed variabel (variabel yang diamati sebagai oprasionalisasi pengukuran atas variabel laten). Setelah sususnan konstruk dan indikatornya dinyatakan dalam 
persamaan, kemudian dengan menggunakan prosedur confirmatory factor analysis dlakukan uji validitas dan reliabilitas.

Uji validitas dilakukan untuk melihat butir-butir pertanyaan mana yang layak (representative) untuk dipergunakan mewakili variabel-variabel bebas yang digunakan dalam studi. Uji ini dilakukan dengan menggunakan analisis faktor konfirmatori (confirmatory factor analysis) pada masing-masing variabel dengan menggunakan program AMOS versi 5. Indikator-indikator dari suatu variabel dikatakan valid jika mempunyai loading factor signifikan pada $(\alpha=5 \%)$. Instrument tersebut undimensional jika mempunyai nilai goodness of fit indeks $(\mathrm{GFI})>0,90$.

Selain harus valid, instrument juga harus reliable (dapat diandalkan). Instrument dikatakan reliabel apabila alat ukur tersebut memperoleh hasil-hasil yang konsisten. Dengan demikian instrumen ini dapat dipakai dengan aman karena dapat bekerja dengan baik pada waktu yang berbeda dan kondisi yang berbeda. Jadi reliabilitas menunjukkan seberapa besar pengukuran dapat memberikan hasil yang relatif tidak berbeda dilakuakan pengukuran kembali terhadap subjek yang sama. Reliabilitas dalam studi ini dihitung menggunakan composite (construct reliability) dengan cut of value minimal sebesar 0,6 (Ghozali, 2005:134). Rumus yang digunakan untuk menghitung reliabilitas konstruk ini adalah sebagai berkut :

Tabel 4.9. Hasil Uji Validitas dan Reliabilitas

\begin{tabular}{|c|c|c|c|c|c|c|}
\hline \multirow{3}{*}{$\begin{array}{l}\text { Variabel } \\
\text { Indikator }\end{array}$} & \multicolumn{5}{|c|}{ Uji Validitas } & \multirow{2}{*}{$\begin{array}{c}\text { Construk } \\
\text { Reliability }\end{array}$} \\
\hline & \multirow{2}{*}{$\begin{array}{c}\text { Loading } \\
\text { faktor }\end{array}$} & \multirow{2}{*}{$\mathrm{CR}$} & \multirow{2}{*}{$\mathrm{P}$} & \multirow{2}{*}{ Ket } & GFI & \\
\hline & & & & & & \multirow[b]{3}{*}{0,850} \\
\hline$X_{11}$ & 0,778 & 11,231 & $* * *$ & Valid & \multirow{7}{*}{$\begin{array}{c}0,939 \\
\text { Valid } \\
\text { Undimension } \\
\text { al }\end{array}$} & \\
\hline$X_{12}$ & 0,819 & * & * & Valid & & \\
\hline$X_{13}$ & 0,831 & 12,390 & $* * *$ & Valid & & \multirow[b]{3}{*}{0,799} \\
\hline$X_{21}$ & 0,753 & 10,337 & $* * *$ & Valid & & \\
\hline$x_{22}$ & 0,809 & * & * & Valid & & \\
\hline $\mathrm{X}_{23}$ & 0,702 & 9,427 & $* * *$ & Valid & & \multirow[b]{3}{*}{0,829} \\
\hline$x_{31}$ & 0,779 & 10,887 & $* * *$ & Valid & & \\
\hline$x_{32}$ & 0,823 & $*$ & $*$ & Valid & \multirow{8}{*}{$\begin{array}{c}0,996 \\
\text { Valid } \\
\text { Undimension } \\
\text { al }\end{array}$} & \\
\hline$x_{33}$ & 0,758 & 10,475 & $* * *$ & Valid & & \multirow[b]{3}{*}{0,853} \\
\hline$x_{41}$ & 0,826 & 11,311 & $* * *$ & Valid & & \\
\hline$x_{42}$ & 0,795 & $*$ & * & Valid & & \\
\hline$x_{43}$ & 0,816 & 11,140 & $* * *$ & Valid & & \multirow[b]{3}{*}{0,901} \\
\hline $\mathrm{Y}_{1}$ & 0,844 & * & * & Valid & & \\
\hline $\mathrm{Y}_{2}$ & 0,874 & 12,859 & $* * *$ & Valid & & \\
\hline $\mathrm{Y}_{3}$ & 0,885 & 12,684 & $* * *$ & Valid & & \\
\hline
\end{tabular}

Sumber: data 2014

Berdasarkan hasil uji validitas dan reliabilitas seperti disajikan dalam Tabel 4.6 menunjukkan bahwa nilai $\mathrm{t}$ (ditunjukkan oleh nilai C.R) untuk loading signifikansi 0,05 (nilai kritis $=1,96$ ), demikian juga nilai probabilitasnya lebih kecil dari $\alpha(0,05)$. Sehingga dapat UNEJ JURNAL XXXXXXXXX 2014, I (1): 1-6 disimpulkan bahwa semua variabel secara signifikan berhubungan dengan konstruk (semua indikator valid). Construct reliability sebesar 0,850, 0,799, 0,829, 0,853 dan 0,901 , berada diatas nilai yang direkomendasikan yakni minimal sebesar 0,60-0,70 dengan demikian semua indikator atau variabel adalah reliabel.

\section{Pembahasan}

\section{Pengaruh Customer Intimasi Terhadap Loyalitas}

\section{Pelanggan}

Penelitian yang dilakukan, menunjukkan bahwa nilai koefisien variabel customer intimasi sebesar 0,294 atau 29,4\%. Customer intimasi sebagai suatu bagian strategi bisnis secara generik yang berhubungan dengan pendekatan strategi pemasaran relasional yang menjadi dasar dari hubungan jasa yang bersifat business to consumer atau hubungan keakraban merupakan bagian strategi bisnis yang membangun kerangka kerja untuk pemasaran relasional antara perusahaan dengan pelanggannya. Hasil penelitian yang telah dilakukan menunjukkan bahwa adanya karyawan yang berkerja pada rumah makan bebek 88 kurang bersedia mendengarkan keluhan pelanggannya sehingga akan menjadikan pelanggan kurang mempunyai rasa dalam merekomendasikan tempat pilihan makannya serta akan menjadikan kurangnya niat pelanggan untuk menggunakan kembali atau membeli produk pada rumah makan bebek 88, kurang adanya rasa berharga atau nilai dari pelangganya bahwa hubungannya dengan tempat pilihan makanannya merupakan hanya kebutuhan yang diinginkan pada saat tertentu sehingga pelanggan enggan untuk merekomendasikan dan menginformasikan mengenai hal positif terhadap rumah makan bebek 88 , adanya pelanggan yang merasa kurang adanya pelayanan yyang diberikan pada saat proses membeli atau mengkonsumsi produk akan menjadikan pelanggan merasa bahwa hubungannya dengan rumah makan bebek 88 hanya hubungan antara penjual dan pembeli tanpa mengakibatkan adanya perubahan rasa pada diri pelanggan sehingga dengan adanya hubungan seperti ini akan mengakibatkan kurangnya partisipasi pelanggan terhadap rekomendasi, penggunaan atau penbelian kembali pada rumah makan bebek 88

\section{Pengaruh Kepercayaan Pelanggan Terhadap Loyalitas Pelanggan}

Penelitian yang dilakukan, menunjukkan bahwa nilai koefisien variabel kepercayaan pelanggan sebesar 0,984 atau 98,4\% dengan arah positif. Kepercayaan pelanggan sebagai keyakinan yang ada dalam benak pelanggan terhadap sebuah penyedia jasa yang handal dan memiliki integritas yang tinggi serta merupakan keinginan pelanggan untuk mempercayakan sesuatu kepada orang lain yang dapat dipercaya dan hal ini muncul dari adanya jasa yang kompeten, konsisten, jujur, dan memberikan pelayanan secara adil kepada pelanggan. Hasil penelitian yang telah dilakukan menunjukkan bahwa adanya layanan yang dirasa berkompeten oleh para pelanggannya sehingga akan menciptakan adanya keyakinan bahwa rumah makan bebek 88 merupakan pilihan yang tepat yang dapat diharapkan dapat menjadi suatu pemenuhan kebutuhan 
pelanggannya dan dengan adanya pelayanan yang dirasa telah kompeten oleh pelanggannya maka pelanggan akan merasakan adanya suatu hubungan yang akan menjadikan pelanggan dapat merekomendasikan atau ingin kembali menggunakan atau membeli produk dari rumah makan bebek 88 , adanya keyaikinan dari pelanggannya bahwa pelayanan yang diberikan merupakan pelayanan prioritas yang konsisten dalam setiap waktu dan diberikan kepada pelanggannya sehingga pelanggan akan merasa yakin bahwa pilihan tempat pemenuhan kebutuhannya adalah tepat yang akan merangsang adanya perilaku keterkaitan serta hubungan relasional pada pelanggannya, dan adanya keyakinan pelanggan terhadap pelayanan dengan kemampuan yang baik yang telah diberikan dan diterimanya akan menciptakan adanya keyakinan pada pelanggan Bebek 88 bahwa pelayanan yang diberikan adalah pelayanan yang memberikan adanya kenyaman pada pelanggan sehingga dengan adanya rangsangan yang sesuai dengan harapan pelanggannya maka akan menciptakan adanya rasa atau hubungan sehingga pelanggan akan senantiasa mengingat pelayanan yang telah diterimanya dan akan dapat memberikan rekomendasi kepada siapa saja yang berhubungan atau membutuhkan pelayanannya.

\section{Pengaruh Komitmen Pelanggan Terhadap Loyalitas} Pelanggan

Penelitian yang dilakukan, menunjukkan bahwa nilai koefisien variabel komitmen pelanggan sebesar 0,783 atau $78,3 \%$ dengan arah positif. Komitmen pelanggan sebagai sifat keinginan yang kuat dari seorang pelanggan untuk melanjutkan hubungan dengan penyedia jasa disertai dengan kesediaan untuk mempertahankan hubungan, dimana hal ini merupakan hal yang penting dalam rangka menjaga hubungan untuk terus menerus menjaga suatu hubungan yang bermakna bagi kedua belah pihak. Hasil penelitian yang telah dilakukan menunjukkan bahwa adanya pelayanan dan kualitas makanan yang baik yang disediakan rumah makan bebek 88 akan meciptakan adanya keinginan yang kuat sebagai komitmen dari pelanggannya untuk tidak berubah-ubah dalam menjaga keinginannya dalam memutuskan pilihannya sehingga dengan adanya komitmen yang baik sebagai hubungannya dengan pelaku penyedia jasa atau produk maka pelanggan akan senantisa berkeyakinan bahwa pilihannya dalam merekomendasikan keyakinannya adalah hal yang wajar, adanya komitmen yang tinggi dari pelanggannya kepada rumah makan bebek 88 akan menjadikan pelanggan merasa merasa peduli terhadap hubungannya dengan pelaku penyedia jasa atau produk sehingga pelanggan akan berkomitmen untuk menginformasikan kepada rumah makan bebek 88 bahwa pelayanan yang ada dan kurang harus senantisa ditingkatkan serta pelanggan akan senantiasa berupaya dalam menginformasikan hal positif mengenai produk yang ditawarkan dirumah makan bebek 88 , dan adanya rasa senang atau suka dari pelanggannya pada produk dan pelayanan serta usaha rumah makan bebek 88 akan merangsang pelanggan untuk tetap dapat mengingat dan merekomendasikan serta mempertahankan hubungannya relasionalnya dengan usaha rumah makan bebek 88 sehingga dengan adanya rasa komitmen dari pelanggan maka rekomendasi yang ada akan selalu cenderung positif didalam menginformasikan produk yang ditawarkan dirumah makan bebek 88

\section{Pengaruh Kepuasan Pelanggan Terhadap Loyalitas Pelanggan}

Penelitian yang dilakukan, menunjukkan bahwa nilai koefisien variabel kepuasan pelanggan sebesar 1,697 atau $167,7 \%$ dengan arah positif. Kepuasan pelanggan sebagai evaluasi pelanggan terhadap suatu penerimaan barang dan jasa atau pengalaman dalam mengkonsumsinya yang mampu menyediakan pemenuhan terkait dengan konsumsi pada tingkat yang menyenangkan. Hasil penelitian yang telah dilakukan menunjukkan bahwa adanya rasa puas dari pelanggan setelah mengkonsumsi makanan dirumah makan bebek 88 menjadikan pelanggan merasa bahwa kebutuhannya telah terpenuhi sehingga dengan adanya rasa puas atau gembira dari pelanggannya maka pelanggan akan senantiasa berfikir positif terhadap pelayanan yang ada dirumah makan bebek 88 sehingga dengan adanya kecenderungan tersebut maka pelanggan akan berkeinginan kembali dalam melakukan proses pembelian ulang atau mengkonsumsi produk pada rumah makan bebek 88, adanya pelanggan yang merasa diuntungkan dengan adanya produk dan pelayanan yang diberikan kepadanya sehingga pelanggan tidak merasa menyesal karena telah menikmati hidangan dirumah makan bebek 88 akan menumbuhkan adanya rasa atau keinginan kepada pelanggan untuk tetap dapat menjaga hubungannya relasionalnya sehingga keinginan pelanggan untuk tetap melakukan proses pembelian makanan dan rekomendasi pada rumah makan bebek 88 akan senantiasa selalu ada, dan adanya pelanggan yang yang telah merasa bahwa kebutuhannya telah telah terpenuhi dan merasa bahwa harapannya telah tercapai akan menjadikan dan merangsang pelanggan untuk tetap berkeinginan dalam melakukan proses pembelian makanan pada rumah makan bebek 88 sehingga dengan adanya frekuensi pembelian atau kunjungan pada rumah makan bebek 88 yang meningkat secara tidak langsung pelanggan akan menyadari bahwa pelayanan yang diberikan tetap dapat memberikan kepuasan pada pelanggannya sehingga dengan adanya hal tersebut maka pelanggan akan senantiasa berlangganan dalam proses pembelian makanan, memiliki pemikiran yang positif terhadap rumah makan bebek 88 serta dapat melakukan rekomendasi kepada kerabatnya untuk memilih tempat pilihan makannya pada rumah makan bebek 88 .

\section{Kesimpulan dan Keterbatasan}

Berdasarkan hasil analisis yang telah dilakukan pada penelitian ini, maka dapat ditarik kesimpulan sebagai berikut ;

a. Customer intimasi memiliki berpengaruh yang tidak signifikan terhadap loyalitas pelanggan atas layanan jasa Bebek 88. Hal ini dapat diartikan menolak adanya temuan bahwa adanya customer intimasi akan berpengaruh didalam meningkatkan loyalitas pelanggan;

b. Kepercayaan pelanggan memiliki berpengaruh terhadap loyalitas pelanggan atas layanan jasa Bebek 88 dengan arah positif. Hal ini dapat diartikan mendukung adanya temuan bahwa adanya kepercayaan pelanggan akan berpengaruh didalam meningkatkan loyalitas pelanggan;

c. Komitmen pelanggan memiliki berpengaruh terhadap loyalitas pelanggan atas layanan jasa Bebek 88 dengan arah positif. Hal ini dapat diartikan mendukung adanya temuan bahwa adanya komitmen pelanggan akan 
berpengaruh didalam meningkatkan loyalitas pelanggan; d. Kepuasan pelanggan memiliki berpengaruh terhadap loyalitas pelanggan atas layanan jasa Bebek 88 dengan arah positif. Hal ini dapat diartikan mendukung adanya temuan bahwa adanya kepuasan pelanggan akan berpengaruh didalam meningkatkan loyalitas pelanggan.

\section{Keterbatasan Penelitian}

Keterbatasan dalam penelitian ini Proses pengumpulan data primer didalam penelitian ini hanya berdasarkan pada 4 lokasi Rumah Makan Bebek 88 yang berada di Kabupaten Jember, balung, bondowoso dan Surabaya, tanpa adanya pembagian atau penentuan jumlah sempel pada masing-masing lokasi penelitian

\section{Ucapan Terima Kasih}

Terima kasih kepada para dosen pembimbing Prof. Dr. R. Andi Sularso, MSM. Dan Dr. Mohammad Dimyati, SE., M.Si yang selalu memberikan arahan dan masukan untuk penelitian ini.

\section{Daftar Pustaka}

Aaker, David A. 1991. Managing Brand Equity:

Capitalizing on The Value of A Brand Name. Simon and

Schuster (Asia) Pte. Ltd. Terjemahan. Aris Ananda. 1997.

Cetakan Pertama. Jakarta. Penerbit Mitra Utama.

Abratt, Russel and Joy Russel. 1999. Relationship Marketing in Private Banking in South Africa.

International Journal of Bank Marketing. Vol. 17. No. 1. pp. 5-19.

Bearry, S.E. 1996. Customer Sales Associate Retail Relationships. Journal of Retailing. Vol. 72. No. 3. pp. 223-247

Bloemer, Josee and Gaby Odekerken-Schroder. 2002. Store Satisfaction and Store Loyalty Explained by Customer - and Store - Related Factors. Journal of Consumer Satisfaction, Dissatisfaction and Complaining Behavior. 15. ABI/INFORM Research. pp 68.

Dimyati, Mohammad. 2009. Analisis SEM Dalam Uji Pengaruh Beberapa Variabel Terhadap Loyalitas Kajian Berbasis Riset Pada Debitur Kredit Usaha Kecil. Edisi Pertama. Jakarta : Mitra Wacana Media

Fedinand, agusty. 2002. Strucural Equation Modeling dalam Peneletian manajemen, edisi 2. Semarang : Badan Penerbi Universitas Diponogoro.

Garbarino, Ellen and Mark S. Johnson. 1999. The Different Roles of Satisfaction, Trust, and Commitment in Customer Relationships. Journal of Marketing. Vol. 63. pp. $70-87$.

Ghozali, Imam. 2005. Model Persamaan Structural Konsep dan Aplikasi dengan Program AMOS versi 5.0. Semarang : Badan Penerbit Universitas Diponegoro.
2008. Model Persamaan Structural Konsep dan Aplikasi dengan Program AMOS versi 16.0.

Semarang : Badan Penerbit Universitas Diponegoro.

Griffin, Jill. 2002. Costumer Loyalty. Jakarta: PT Erlangga.

Gronroos, Christian. 1994. From Marketing Mix to Relationship Marketing - Towards a Paradigm Shift in Marketing. Management Decisions. Vol. 32. No. 2. pp. 420 .

1997. Keynote paper : From Marketing Mix to Relationship Marketing - Towards a Paradigm Shift in Marketing. Management Decisions. Vol. 35. No. 4.

Gummesson, Evert. 2000. Total Relationship Marketing. Second Edition. Butterworth-Heinemann. Elsevier Science. Woburn MA.

Harsfield, Del I., Roger J. Best, and Kenneth A. Coney. 2000. Consumer Behavior: Building Marketing Strategy. Ninth Edition. Singapore. McGraw Hill.

Hennig-Thurau, Thorsten and Alexander Klee. 1997. The Impact of Customer Satisfaction and Relationship Quality on Customer Retention. Psychology and Marketing. December.

Hoffman, Nicole Ponder. 2002. The Theory of Keakraban : Towards An Understanding of Relationship Marketing In A Professional Sevice Setting. UMI Microform 3027353. Bell and Howell Information and Learning Company.

Keevaney, Warren J. Sandra E. Moriarty, and Thomas R. Duncan. 1995. Marketing. Second Edition. Englewood Cliffs, New Jersey. Prentice Hall, Inc.

Morgan, Robert M. and Shelby D. Hunt. 1994. The Commitment-Trust Theory of Relationship Marketing. Journal of Marketing. Vol. 58. pp. 20-38.

Mooman, C., Gerald Zaltman, and Rohit Deshpande. 1993. Relationship Between Providers and Users of Marketing Research : The Dynamics of Trust Wwithin and Between Organization. Journal of Marketing Research. August.

Oliver, Richard L. 1999. Satisfaction: A Behavioral Perspective on The Consumer. International Edition. Singapore. The McGraw-Hill Companies, Inc.

Oxford, Concise Dictionary. 2005.

Pudjiharjo, w.,j. 2004. Custumer relationship marketing (CRM) sebagai sulusi ektensi industri pelayanan kesehatan dimasa depan. Makalah seminar. Fakultas kesehatan masyarakat, universitas airlangga.

Ratnasari, Ririn Tri. 2005. Patient Intimacy dan Kepuasan : Anteseden Loyalitas Melalui Kepercayaan dan Komitmen Pasien Pada Industry Klinik Perawatan 
Kesehatan (peraktek dokter kesehatan) Di Surabaya. Tesis. Pasca Sarjana Universitas Airlangga

Rutledge, Robert and Patricia Nascimento. 1996. Satisfaction with HMO's. Journal of Health Care Marketing. Vol. 16. No. 1. pp. 22-27.

Schiffman, Leon G. and Leslie Lazar Kanuk. 2004. Consumer Behavior. New Jersey. Prentice Hall International, Inc.

Schurr, Jagdish N. and Ozanne Parvatiyar. 1995. Relationship Marketing in Consumer Markets : Antecedents and Consequencies. Journal of The Academy of Marketing Science. Vol. 23. No. 4. pp. 255-271.

Shemwell, Donald J., Ugur Yavas, and Zeyneb Bilgin. 1998. Customer-Service Provider Relationships : An Empirical Test of A Model of Service Quality, Satisfaction, and Relationship-Orientef Outcomes. International Journal of Service Industry Management. Vol. 9. No. 2. pp. 155-168.

Silverhart, Todd A. 2004. A Question of Trust. LIMRA's Marketfacts Quarterly. Winter. Vol. 23. No. 1.

Sugiyono. 2008. Metode Penelitian Bisnis. Bandung : Alfabeta.

Sumarni, Murti. 2003. Pengantar Bisnis. Edisi Kelima. Yogyakarta: Liberty.

Tjiptono, F., 2005, pemasaran jasa, cetakan pertama, malang, banyumedia, publishing

Ullrich, D. 1994. Tie The Corporate Knot : Gaining Complete Customer Commitment. Sloan Management Review. Vol. 30. Summer. pp. 19-27.

Webster Jr., Frederick E. 1994. Market Driven Management: Using The Marketing Concept to Create A Customer Oriented Company. New York. John Wiley and Sons, Inc.

Zeithaml, Valarie A. 1988. Consumer Perceptions of Price, Quality, and Value: A Means-End Model and Synthesis of Evidence. Journal of Marketing. Vol.52. (July). pp. 2-22. 